Check for updates

The BMJ

Cite this as: BMJ 2021;373:n1046 http://dx.doi.org/10.1136/bmj.n1046 Published: 21 April 2021

\section{Covid-19: Unusual blood clots are "very rare side effect" of Janssen vaccine, says EMA}

\author{
Elisabeth Mahase
}

A possible link exists between very rare cases of unusual blood clots with low blood platelets and the Janssen (Johnson \& Johnson) covid-19 vaccine, but the benefits still outweigh the risks, the European Medicines Agency (EMA) has said.

The EMA's Pharmacovigilance Risk Assessment Committee has reviewed all available evidence including eight cases reported in the US, one of which had a fatal outcome. As of 13 April 2021 over seven million people had received Janssen's one dose vaccine in the US. A warning about the clots will be added to the product information, describing them as a "very rare side effect."

This comes after the EMA investigated similar cases in people who had received the Oxford-AstraZeneca covid-19 vaccine and concluded that the blood clots with low blood platelets were a "possible" and "extremely rare" side effect. ${ }^{1}$ Both vaccines use adenovirus vectors.

Janssen announced that on 13 April it had "proactively delayed" the rollout of its vaccine in Europe, which was due to start that week. US regulators have also paused rollout, and their investigations are ongoing. ${ }^{2}$ When asked why the EMA came to a decision before the US did, Emer Cooke, the agency's executive director, said that it had experience of looking at this issue because of its previous AstraZeneca investigations.

For both vaccines, the EMA has said that a plausible explanation for the unusual combination of blood clots and low blood platelets is an immune response leading to a condition similar to one seen sometimes in patients treated with heparin, called heparin induced thrombocytopenia.

\section{Symptoms}

All US cases relating to the Janssen vaccine occurred in people aged under 60 within three weeks post-vaccination, and the majority were in women. However, the Pharmacovigilance Risk Assessment Committee said that there was not yet enough evidence to determine specific risk factors for these clots.

The blood clots occurred mostly at unusual sites in the body, such as in veins in the brain (cerebral venous sinus thrombosis) or in the abdomen (splanchnic vein thrombosis) and in arteries, together with low levels of blood platelets and sometimes bleeding.

As of 4 April the EMA said that eight cases had been reported after receiving the Janssen vaccine (all in the US), 287 cases were reported after the AstraZeneca vaccine (142 in the European Economic Area), 25 after Pfizer's vaccine, and five after Moderna's.
Commenting on the AstraZeneca figure, Sabine Straus, chair of the Pharmacovigilance Risk Assessment Committee, said, "People in Europe are very aware of it, and we will probably receive more reports now. So, the reporting might be more aligned with the occurrence." Additional studies into these unusual blood clots are being carried out by AstraZeneca, Janssen, and the EMA.

People have been told to seek urgent medical attention if they have any of the following symptoms in the three weeks after vaccination with the Janssen covid-19 vaccine:

- Shortness of breath

- Chest pain

- Leg swelling

- Persistent abdominal pain

- Neurological symptoms, such as severe and persistent headaches or blurred vision; or

- Tiny blood spots under the skin beyond the site

1 Mahase E. AstraZeneca vaccine: Blood clots are "extremely rare" and benefits outweigh risks, regulators conclude. BMJ2021;373:n931. doi: 10.1136/bmj.n931 pmid: 33832929

2 Mahase E. Covid-19: US suspends Johnson and Johnson vaccine rollout over blood clots. BM/2021;373:n970.

This article is made freely available for use in accordance with BMJ's website terms and conditions for the duration of the covid-19 pandemic or until otherwise determined by BMJ. You may use, download and print the article for any lawful, non-commercial purpose (including text and data mining) provided that all copyright notices and trade marks are retained. of the injection. doi: 10.1136/bmj.n970 pmid: 33849896 